\title{
Estudio múltiple de tornados del 4 de marzo de 2018 en Andalucía occidental
}

https://doi.org/10.31978/639-19-010-0.461

\author{
Juan de Dios Soriano Romero' (jsorianor@aemet.es) \\ Delia Gutiérrez Rubio² (dgutierrezr@aemet.es)
}

${ }^{1}$ AEMET / Delegación Territorial en Andalucía, Ceuta y Melilla

${ }^{2}$ AEMET / Área de Información Meteorológica y Climatológica

\begin{abstract}
RESUMEN
La tarde del 4 de marzo de 2018 se produjeron al menos tres tornados en Andalucía occidental, uno en El Puerto de Santa María (Cádiz) y dos en la provincia de Huelva. El tornado de El Puerto alcanzó una intensidad EF2 en la escala mejorada de Fujita. Uno de los de Huelva también alcanzó esa intensidad, mientras que el otro se quedó en EF1, pero es probablemente el tornado más largo del que se tengan registros en España, con un recorrido de unos $28 \mathrm{~km}$ por territorio nacional. Con toda probabilidad y a partir de las informaciones proporcionadas por el IPMA se trata del mismo tornado que atravesó parte del Algarve ese mismo día, con lo que la trayectoria tendría una longitud aproximada de $48 \mathrm{~km}$. Este episodio constituye un ejemplo típico de oleada de tornados en el suroeste peninsular, en una situación de ligera inestabilidad, elevada cizalladura, alta helicidad y niveles de condensación bajos. Estas situaciones, relativamente frecuentes en la estación fría, en ocasiones favorecen la aparición de convección relativamente somera, pero con algunas características supercelulares, como signos de rotación persistentes en altura coincidentes con ganchos en la imagen de reflectividad y otros elementos característicos de las supercélulas típicas.
\end{abstract}

PALABRAS CLAVE: tornado; mesociclón; supercélula de topes bajos; escala Fujita mejorada; helicidad; CAPE3; cizalladura.

\section{INTRODUCCIÓN}

Dentro de la distribución de tornados de la España peninsular, un máximo relativo se registra en las costas del suroeste peninsular y zonas bajas adyacentes (RIESCO et al., 2015). En estas zonas, la mayor parte de los tornados se producen alrededor de la estación fría, particularmente entre octubre y marzo (fig. 1). La llegada de borrascas atlánticas favorece la existencia de una elevada cizalladura vertical de viento, sobre todo en niveles bajos. Junto a ello, la relativamente elevada temperatura del mar en el golfo de Cádiz permite la existencia de una ligera inestabilidad que puede extenderse hacia el interior con los vientos del suroeste predominantes en esas situaciones.

Estos entornos, HSLC (High Shear Low Cape) por sus siglas en inglés, son reconocidos como favorables para la ocurrencia de convección severa y particularmente tornados (SHERBURN y PARKER, 2014), dado que además concurre la circunstancia favorable de unos niveles de condensación bajos (debido a la elevada humedad en capas bajas). Estos tornados pueden ocurrir asociados a diversos tipos de estructuras. A veces se forman en líneas de turbonada o sistemas convectivos lineales. En ocasiones, incluso sobre frentes donde apenas hay convección en la misma línea frontal. También de forma relativamente frecuente, como en el caso de estudio que se trata en este trabajo, se forman asociados a supercélulas de topes bajos o minisupercélulas, 


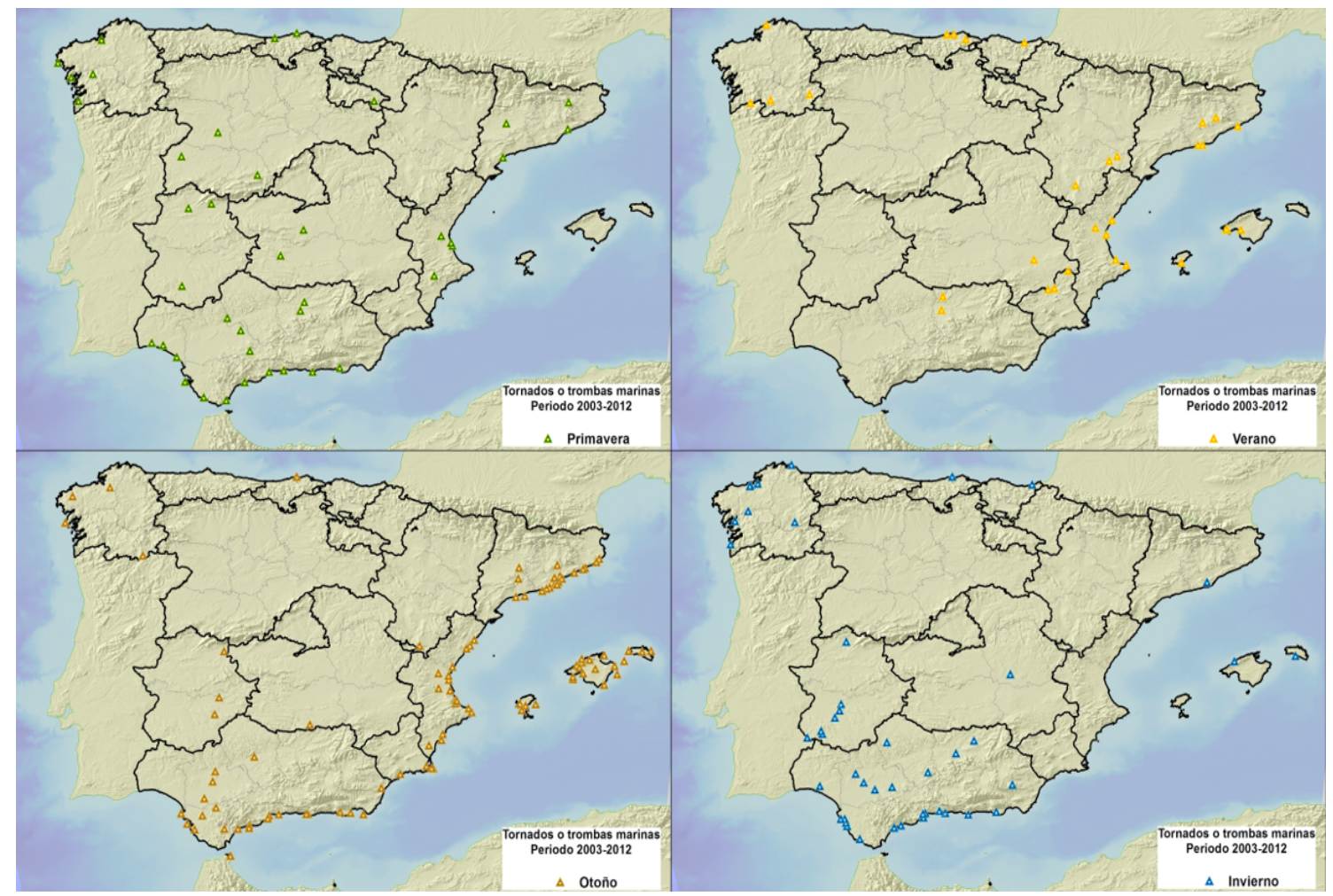

Figura 1. Distribución estacional de tornados y trombas marinas en el periodo 2003-2012, extraído de Riesco et al. (2015).

células convectivas con una corriente de ascenso en rotación y características formales similares a las grandes supercélulas, pero mucho más sutiles (Burgess et al., 1995), (Markowsky y Straka, 2000), (DAVIS y PARKER, 2014). Dada su escasa altura, en ocasiones no producen descargas eléctricas ni granizo, de modo que a veces, el único efecto destacable en superficie es el tornado.

A principios de marzo de 2018 se produjo uno de estos episodios. En medio de una sucesión de temporales del oeste, con fuertes rachas de viento e intensas precipitaciones, el 4 de marzo nuevas bandas nubosas penetraban por las costas del golfo de Cádiz. A lo largo de la tarde aparecen noticias en redes sociales y prensa de internet acerca de la posible ocurrencia de tornados en el Algarve y puntos próximos al litoral de

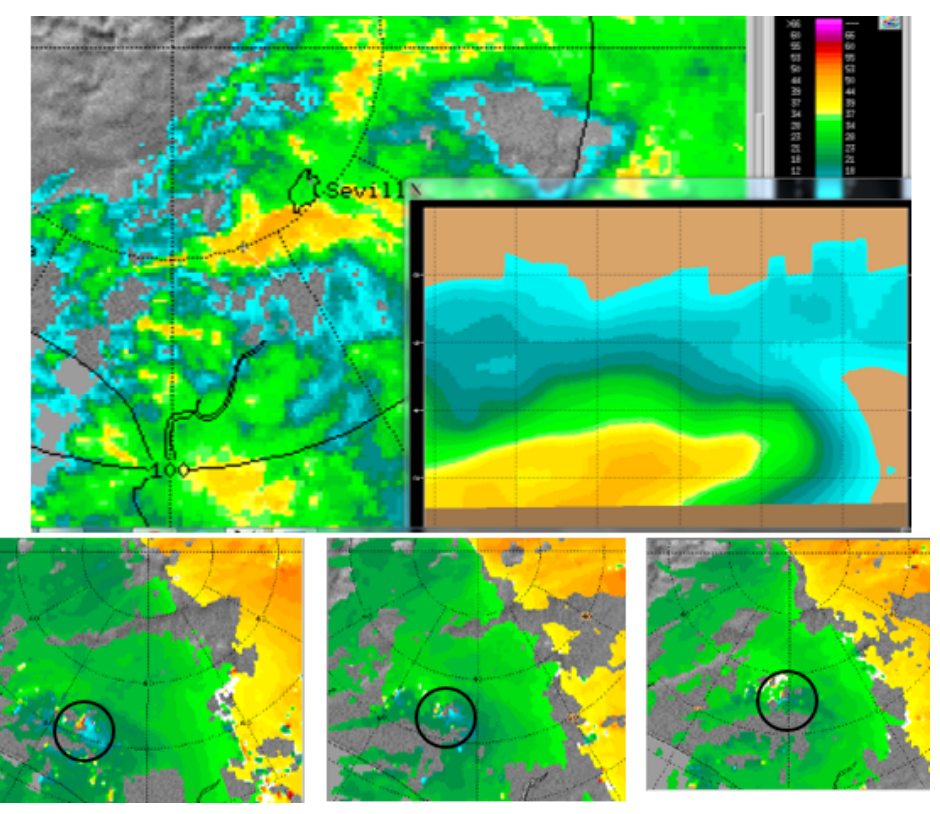

Figura 2.

Imágenes radar del tornado EF2 del 11/11/2014 que recorrió $25 \mathrm{~km}$ por el Bajo Guadalquivir (extraído de Soriano y GutiérRez, 2016). Se pueden observar elementos típicos de las supercélulas, como inflow notch, $V$ notch, gancho en la horizontal y zonas abalconadas en la vertical, aunque las dimensiones horizontales y verticales de la célula son mucho más pequeñas que las de las supercélulas típicas. 


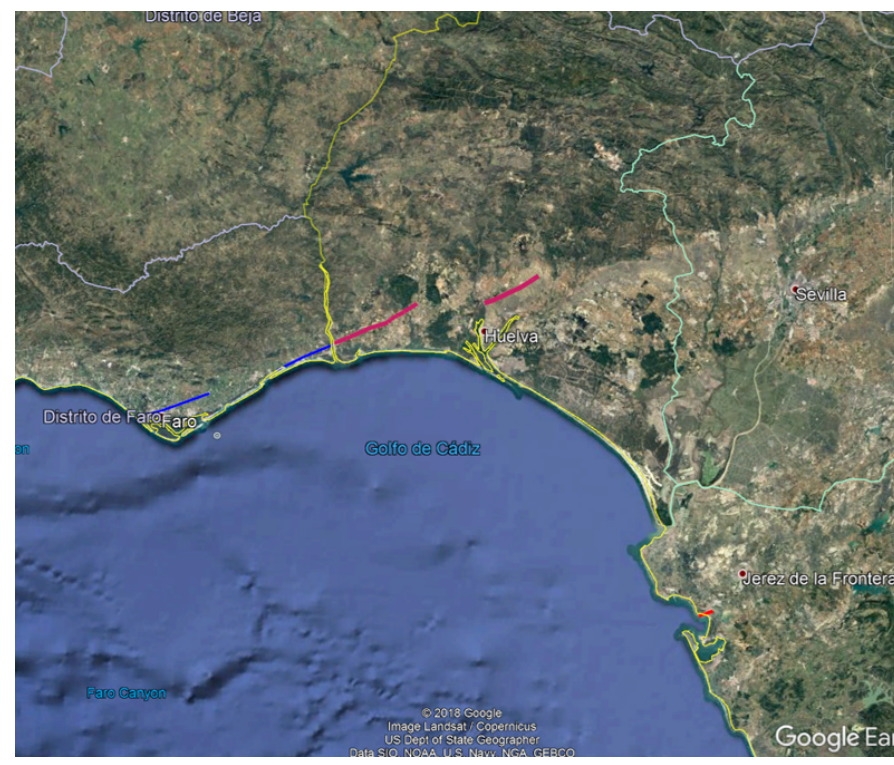

Figura 3. Trayectorias de tornados identificadas por AEMET (rojo) e IPMA (azul, fuente Paulo Jorge Pinto), la tarde del 4 de marzo de 2018.

Huelva, incluso con fotos y vídeos del o de los fenómenos. Más tarde comienzan a aparecer también informaciones sobre un posible tornado que habría afectado a Puerto Sherry, en El Puerto de Santa María, un poco más tarde, causando importantes daños. En la figura 3 puede verse la trayectoria aproximada de los tornados de ese día. El estudio de este episodio tiene un triple interés. Primero, se trata de un caso típico de episodio múltiple de tornados en la estación fría en el suroeste peninsular. Segundo, se producen el mismo día dos tornados de intensidad EF2. Tercero, el otro tornado, de intensidad EF1, es el de mayor longitud de los que se tienen registrados en España (al menos hasta donde es conocido por los autores), llegando a $48 \mathrm{~km}$ incluyendo la primera parte de su recorrido por el Algarve portugués.

En este trabajo se analizarán las características principales de la situación sinóptica y una serie de parámetros convectivos útiles. Se detallarán las características de cada uno de los tornados, a partir de las visitas de campo realizadas, los datos aportados por el IPMA, el Consorcio de Compensación de Seguros y otras fuentes oficiales, así como vídeos y fotos aparecidos en redes sociales. Finalmente se expondrán a modo de resumen una serie de conclusiones.

\section{SITUACIÓN METEOROLÓGICA. PARÁMETROS CONVECTIVOS}

La situación meteorológica del día 4 de marzo a las 18 UTC presentaba una vaguada al oeste de la Península, con flujo difluente sobre Andalucía occidental en niveles altos (fig. 4.a), a la salida de un par de chorros de viento, lo que proporcionaba inestabilidad dinámica. En niveles medios existía algo de aire frío sobre el suroeste peninsular (fig 4.b), también con difluencia marcada. En niveles bajos destacaba el flujo húmedo y relativamente cálido del suroeste, lo que junto a la situación de niveles medios (fig. 4.c) favorecía la existencia de una cierta inestabilidad térmica. También era importante la cizalladura, no solo de intensidad de viento, sino también direccional en niveles bajos.

Estos ingredientes esenciales para el desarrollo de la convección en el episodio que nos ocupa se aprecian perfectamente en el perfil vertical sobre un punto cercano al litoral de Huelva (fig. 5). En él se observa cómo

a)

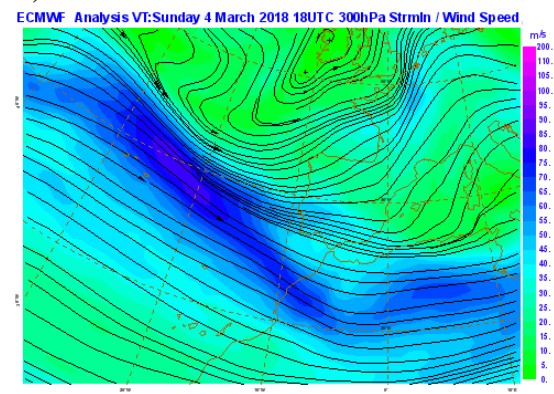

b)

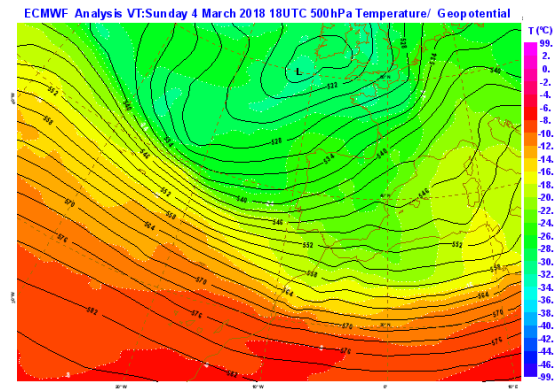

c)

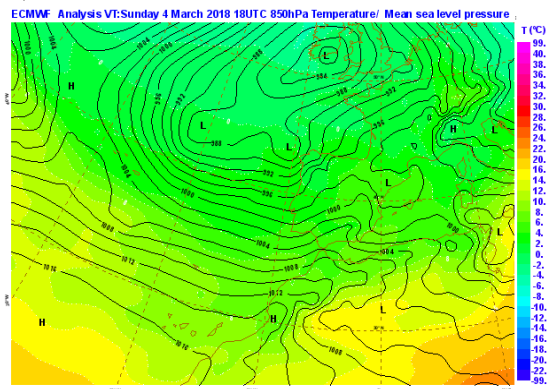

Figura 4. Análisis de las 18 UTC del día 4 del modelo IFS del ECMWF. a) Líneas de corriente e isotacas en $300 \mathrm{hPa}$. b) Altura geopotencial y temperatura en $500 \mathrm{hPa}$. c) Presión reducida al nivel del mar y temperatura en $850 \mathrm{hPa}$. 

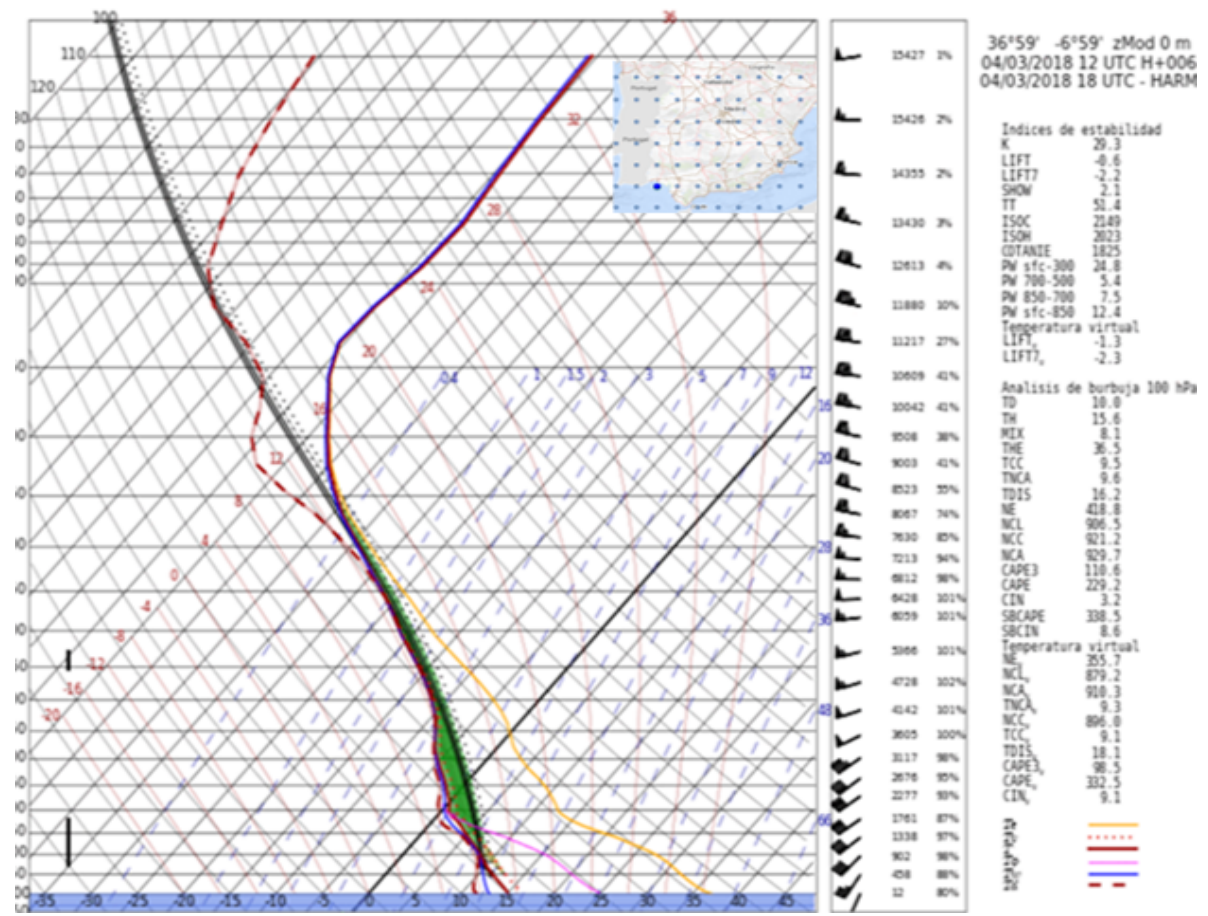

Figura 5.

Modelo ECMWF. Pasada del día 4/3/18 las 12 Z. Pronóstico HH+06.

Perfil vertical previsto sobre un punto próximo al litoral central de Huelva.
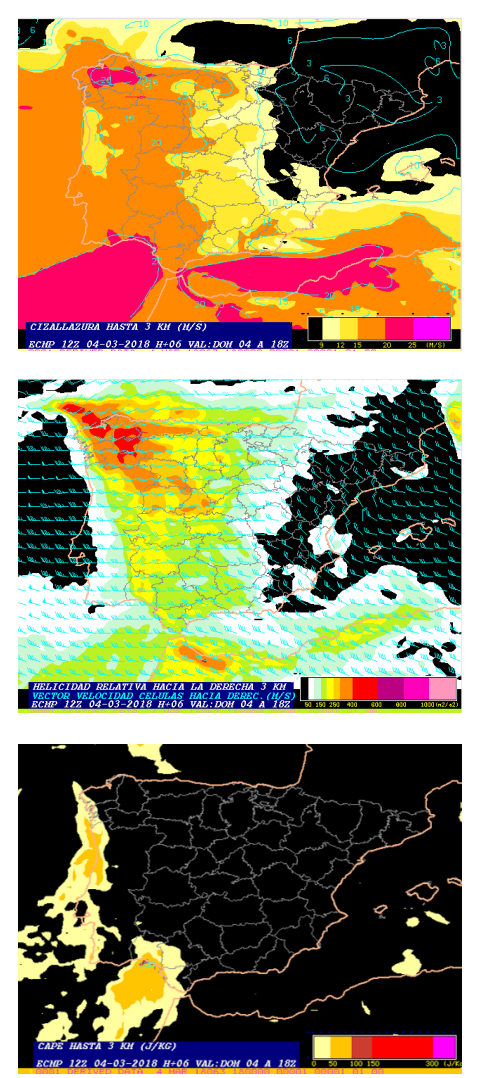

el viento gira en sentido anticiclónico con la altura en niveles bajos, intensificándose hasta unos 50 kt a $4000 \mathrm{~m}$ de altura, a la vez que se aprecia la existencia de un ligero CAPE concentrado en las capas más bajas. La humedad es muy elevada en niveles bajos, lo que se traduce en bajos niveles de condensación. Este último es un ingrediente considerado generalmente importante para la ocurrencia de tornados, particularmente en entornos de bajo CAPE (GUYER y DEAn, 2010).

En forma de mapas, se observa a las 18 UTC (fig. 6) en las costas del golfo de Cádiz una elevada cizalladura vertical en los $3 \mathrm{~km}$ más bajos (superior a $20 \mathrm{~m} / \mathrm{s}$ ), con un valor de helicidad relativa hacia la derecha también significativo (más de $200 \mathrm{~m}^{2} / \mathrm{s}^{2}$ en puntos del litoral). Todo ello junto con un CAPE en los $3 \mathrm{~km}$ más bajos del orden de $100 \mathrm{~J} / \mathrm{kg}$, suficiente (WICKER y CANTRELL, 1996) para el levantamiento y conversión de la vorticidad horizontal asociada a la cizalladura vertical en vorticidad vertical, favoreciendo la aparición de rotación en las corrientes verticales ascendentes.

a)

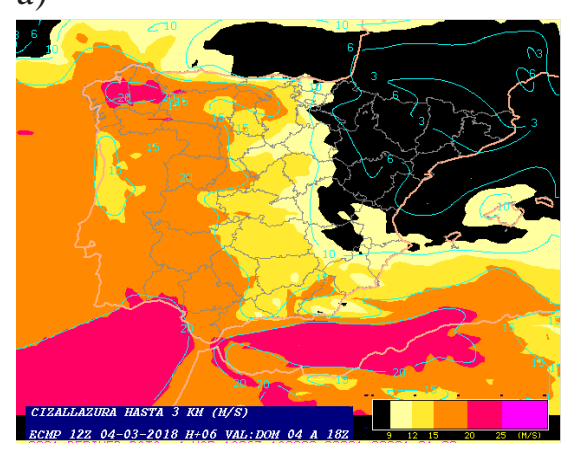

b)

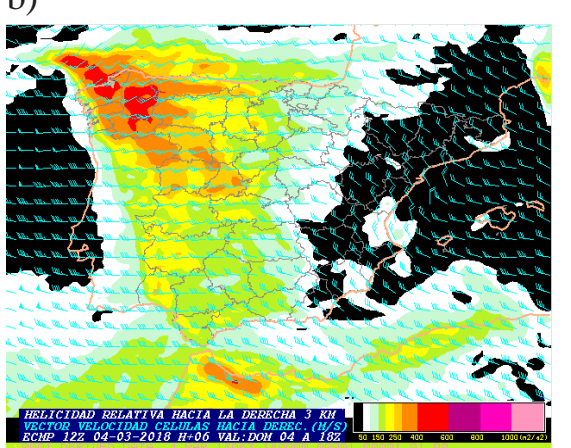

c)

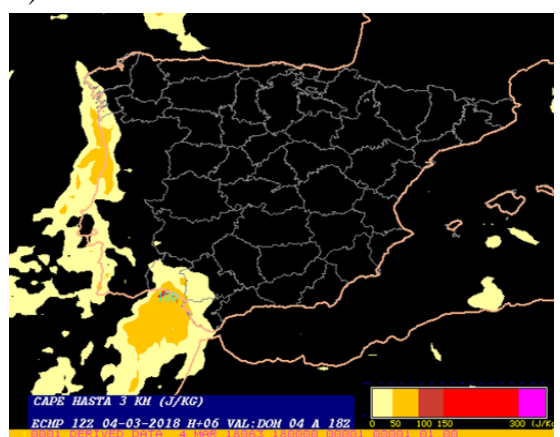

Figura 6. Modelo ECMWF. Pasada del día 4/3/18 a las 12Z. Pronóstico HH+06.

a) Cizalladura vertical $(\mathrm{m} / \mathrm{s})$ en los 3 primeros kilómetros. b) Helicidad relativa hacia la derecha $\left(\mathrm{m}^{2} / \mathrm{s}^{2}\right)$ en los 3 primeros kilómetros. c) CAPE (J/kg) en los 3 primeros kilómetros. 


\section{TORNADOS DE HUELVA Y EL ALGARVE}

En las imágenes de satélite de la tarde del día 4 (fig. 7) se observa una banda frontal con pequeñas células desarrolladas embebidas, sobre todo al sur de la misma. Destacan los penachos de cirros de las pequeñas células, orientados hacia el este-sureste, denotando la importante cizalladura vertical de viento existente. Una de esas células, formada antes de las 14 UTC penetró en tierra cerca de Faro un poco más tarde. Durante su ciclo de vida, de unas 4 horas, atravesó el resto del Algarve hacia el este y gran parte de la provincia de Huelva. En las imágenes de reflectividad del radar de Loulé (fig. 7) puede observarse como mantiene su identidad durante todo su recorrido, mostrando en ocasiones algunos signos típicamente supercelulares, como un pequeño gancho en la horizontal (fig. 8c).

Asociados a esta célula estarían los tornados reportados en el Algarve y el primero de los de Huelva, desde Ayamonte hasta Cartaya. A partir de los datos de daños recogidos por el IPMA y la visita de campo que realizó uno de los autores en el recorrido Ayamonte-Cartaya, se observa una continuidad en los daños, solo interrumpida por zonas de marisma, sin posibles impactos, entre el tornado de Altura y el de Ayamonte-Cartaya, por lo que es muy probable que se tratara del mismo tornado, que habría recorrido $48 \mathrm{~km}$ en total, convirtiéndose en el de trayectoria más larga del que existen re-
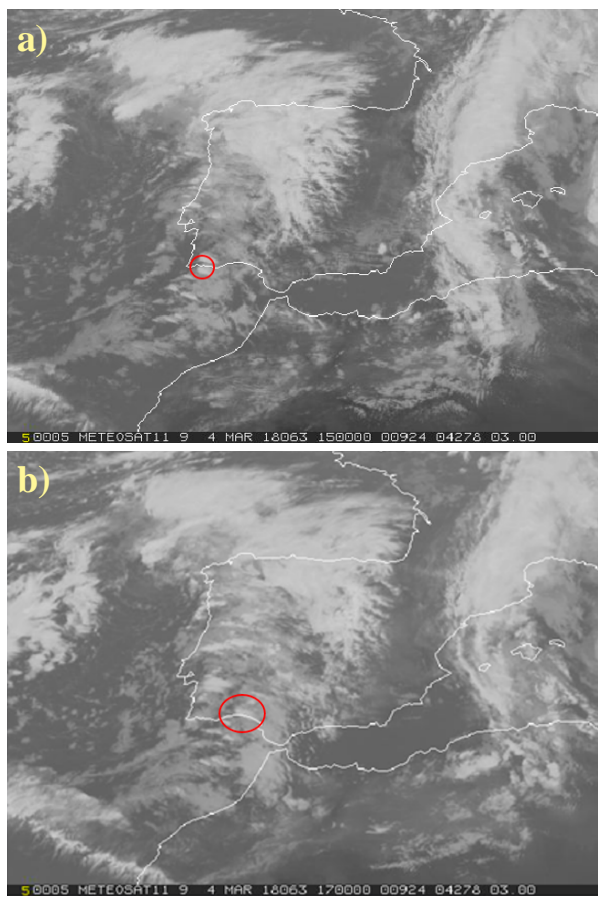

Figura 7. Imágenes del canal IR10,8 de METEOSAT 11. a) A las 15 UTC. b) A las 17 UTC. gistros en España, hasta donde tienen conocimiento los autores.

A partir de las 16:35 UTC aparece una segunda célula justo al sur de la primera (fig. 8d). Ambas células se desplazarán hacia el oeste atravesando la provincia de Huelva. La segunda cobrará protagonismo una vez se debilite la primera, y producirá el último de los tornados, entre Huelva y Beas, de unos $18 \mathrm{~km}$ de recorrido. En las imágenes del radar de Sevilla (fig. 9) se puede apreciar en varias de las células convectivas de dicha tarde signos de rotación en las imágenes de viento radial, además de otros patrones propios de supercélulas en las imágenes de reflectividad, como abalconamiento en la vertical o gancho en la horizontal. En todo caso los signos son muy sutiles, dadas las reducidas dimensiones de las células y la relativa lejanía del radar.
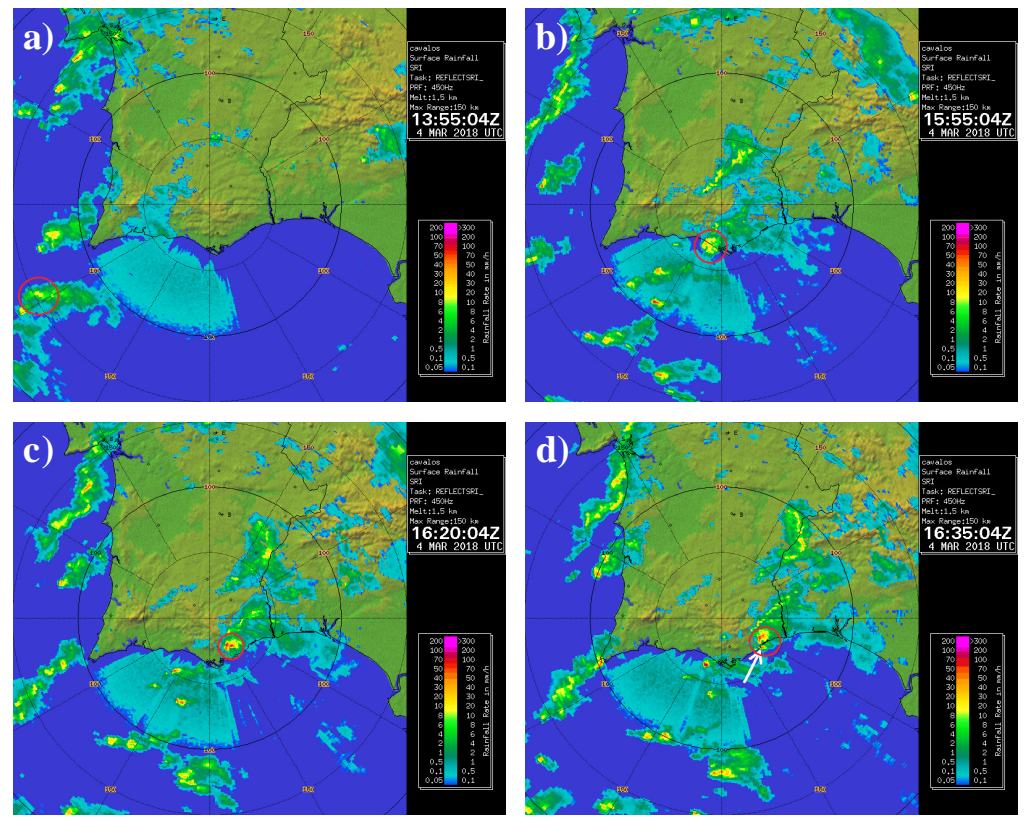

Figura 8.

Radar de Loulé. Producto SRI de reflectividad. a) Imagen de las

13:55 UTC. b) Imagen de las 15:55 UTC. c) Imagen de las 16:20 UTC. d) Imagen de las 16:35 UTC.

Se señala con un círculo rojo la célula desarrollada a la que se asociaron los tornados de Faro y Altura-Cartaya, y con una flecha (última imagen), la segunda célula que aparece al sur de la primera y que generará el tornado de Huelva-Beas varias horas más tarde. A partir de imágenes facilitadas por Paulo Jorge Pinto (IPMA). 
a)

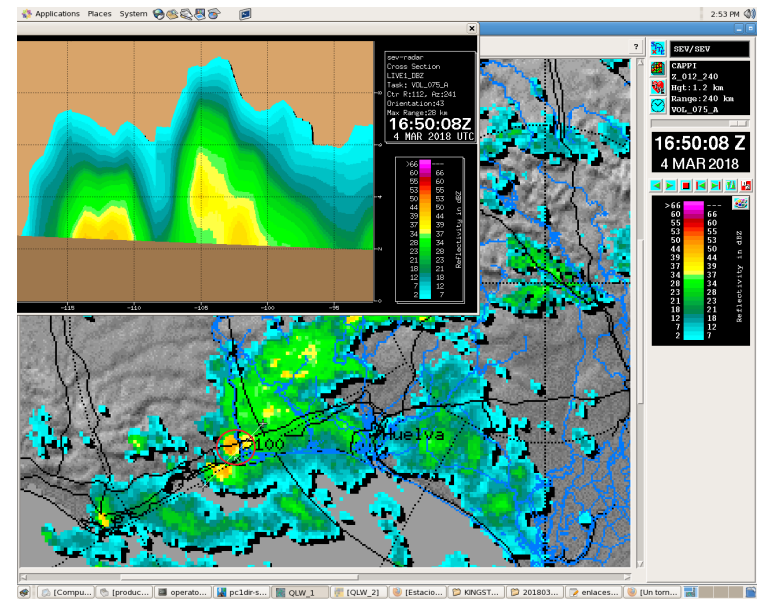

b)

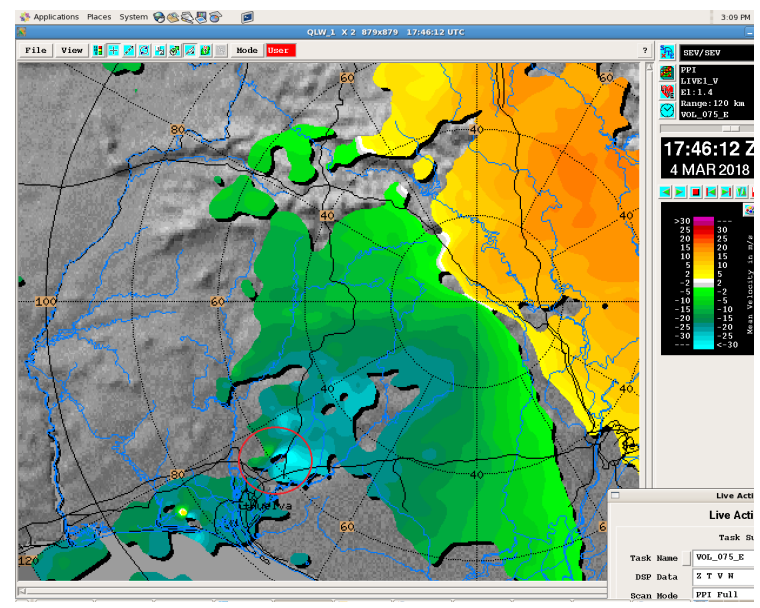

Figura 9. Radar de Sevilla. a) 16:50 UTC. Imagen CAPPI de reflectividad (1200 m en la zona de estudio) y corte vertical. Se marca con un círculo rojo la célula asociada al tornado de Ayamonte. b) 17:46 UTC PPI de viento radial. Elevación 1,4 (aproximadamente $2000 \mathrm{~m}$ de altura en la zona de estudio).

Imagen ligeramente suavizada para minimizar ruido. Se marca con un círculo rojo el dipolo correspondiente a la célula responsable del tornado de Huelva-Beas, en ese momento muy cerca de Trigueros, donde se produjeron los mayores daños. Al suroeste de la misma puede verse otro dipolo.

Es destacable que los máximos de reflectividad se observan a escasos $4 \mathrm{~km}$ de altura, mientras el ECHOTOP de $12 \mathrm{dBz}$ apenas supera los $8 \mathrm{~km}$, valores que, si bien son muy inferiores a los de las supercélulas típicas, están muy en la línea de las llamadas minisupercélulas o a veces low topped supercells (por ejemplo en KENNEDY et al., 1993).

\subsection{Tornado de Ayamonte-Cartaya. Efectos en superficie}
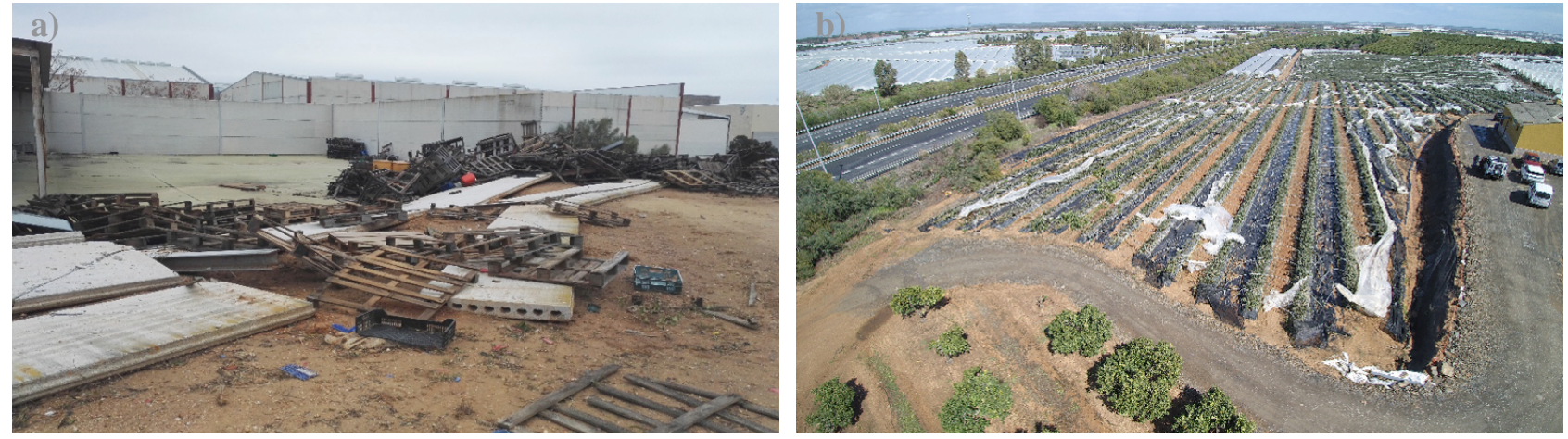

Figura 10. Imágenes de daños. a) Cerramiento de una nave en el polígono industrial La Gravera, de Lepe (Huelva). b) Invernaderos cercanos a dicha zona.

En la visita de campo realizada tres días después del episodio se identificaron daños por viento desde el río Guadiana hasta el término de Cartaya, alineados de forma aproximadamente paralela a la autovía A-49. Aunque no se pudo inspeccionar la totalidad de la trayectoria, dada su longitud (unos $28 \mathrm{~km}$ ), se hicieron numerosos cortes transversales a la misma, encontrando daños en todos los casos. Ello, junto a los testimonios recabados, hace considerar muy probable que la traza fuese continua a lo largo de todo el recorrido, aunque el grado de los daños fuese variable. Se observó afectación a arbolado, cubiertas y cerramientos de viviendas y naves, plásticos y estructura de invernaderos. Los daños aparentemente más intensos se localizaban en el polígono industrial La Gravera, en Lepe, con una nave muy afectada, sobre todo un cerramiento de hormigón derribado (fig. 9), aunque probablemente cedieron las juntas metálicas del mismo. En la misma zona hay mucha afectación a señalización, farolas... La anchura de la traza es variable, entre 150 y 200 m, 
aunque en algunas zonas llega incluso a más de $300 \mathrm{~m}$. La gran longitud de la trayectoria sugiere una intensidad EF2 (BROOKS, 2004), si bien no se encontraron daños que justifiquen una intensidad mayor que la parte alta de EF1, por lo que esta es la intensidad estimada del mismo. En la parte portuguesa del recorrido no se ha hecho hasta ahora una estimación concreta de la intensidad basada en la escala EF, si bien se nos transmite la impresión de que pudiera haber llegado a EF2. En la figura 10 puede verse la localización de los daños registrados en la visita de campo e informaciones posteriores.

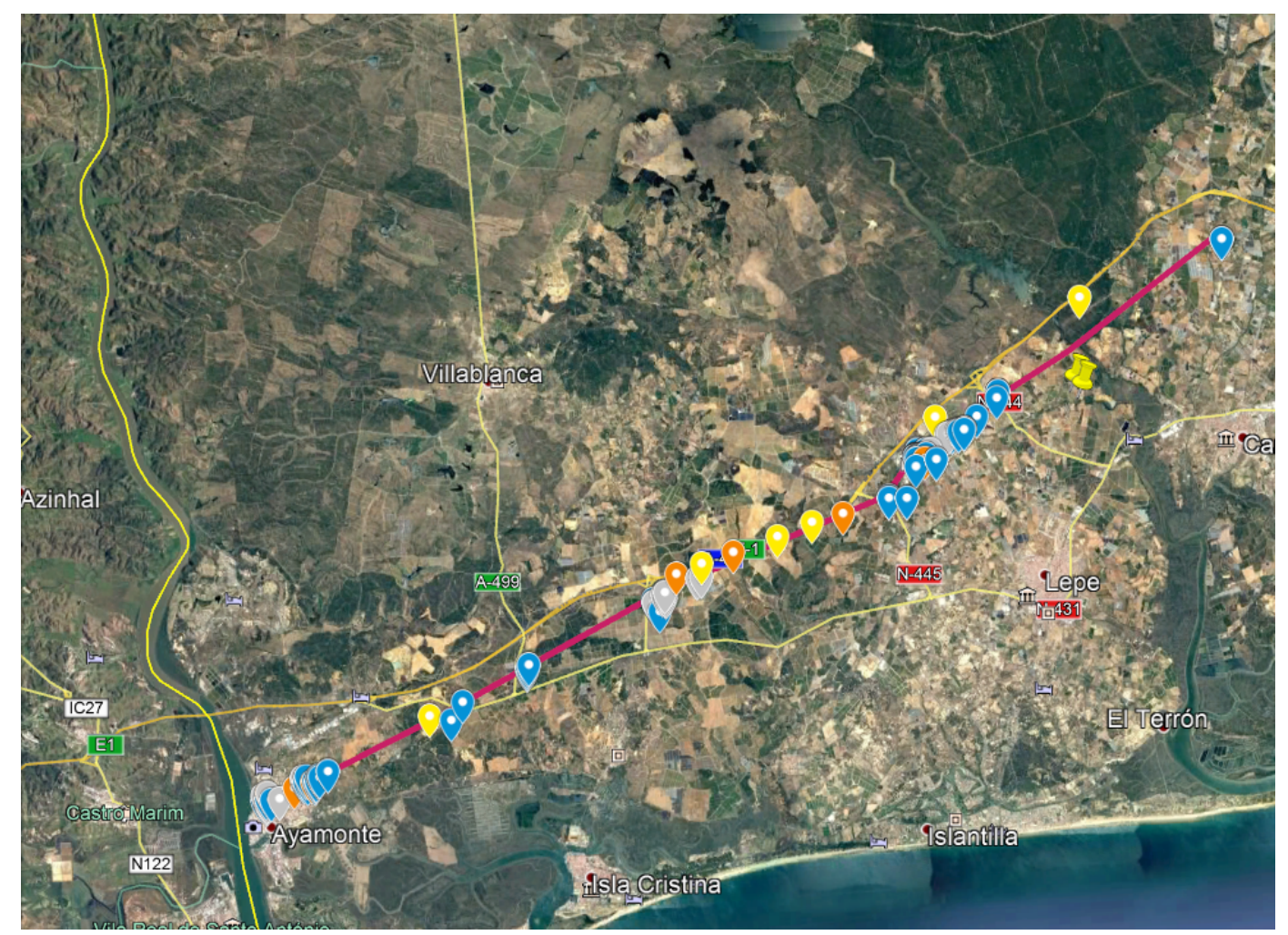

Figura 11. Localización de daños conocidos del tornado Ayamonte-Cartaya.

\subsection{Tornado de Huelva-Beas. Efectos en superficie}

En la visita de campo se identificaron daños por viento desde un pinar en la carretera San Juan del Puerto-Gibraleón hasta Trigueros. A partir de dichos daños, junto con la información de testigos, ayuntamientos y una peritación del Consorcio de Compensación de Seguros se deduce la existencia de una trayectoria continua entre dichos puntos, que se extendería después hacia el término municipal de Beas, donde según el ayuntamiento 3500 olivos resultaron afectados. El recorrido total de este tornado habría sido de unos $18 \mathrm{~km}$ y su intensidad habría alcanzado EF2, con los daños más importantes en el pinar inicial y en una nave industrial en Trigueros que resultó casi destruida (fig. 12), junto a la cual también hubo grandes daños en arbolado.
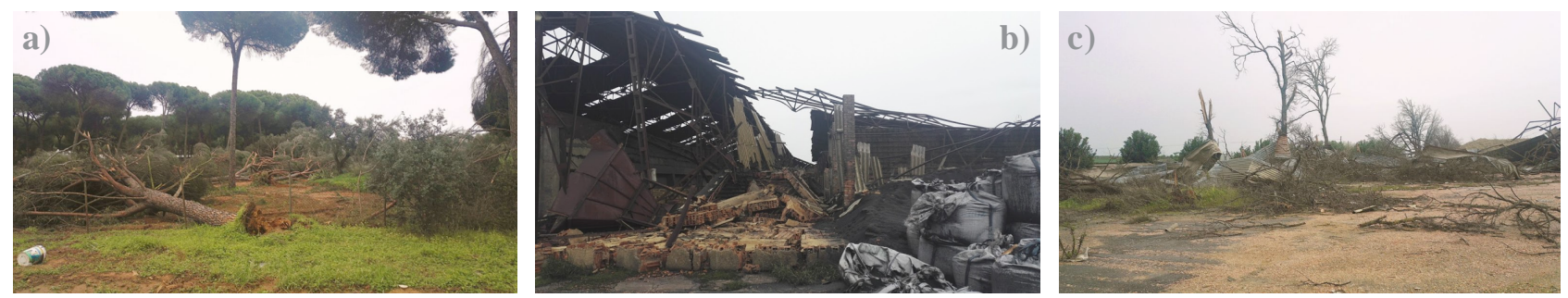

Figura 12. Imágenes de daños del tornado Huelva-Beas. a) En un pinar en la zona de Peguerillas.

b) y c) En una fábrica de ladrillos plenamente operativa en Trigueros y sus alrededores. 


\section{TORNADO DE EL PUERTO DE SANTA MARÍA}

Una célula con características similares a las anteriores (fig. 13) fue la que produjo el tornado de El Puerto de Santa María. En las imágenes del radar de Sevilla (fig.14) se puede observar cómo está formada al menos desde más de una hora antes de tocar tierra, mostrando altos valores de reflectividad en el extremo oeste, un penacho orientado al este denotando la cizalladura vertical y una clara individualidad mantenida durante todo su ciclo de vida, aun encontrándose inmersa en una amplia área de precipitaciones. En algunas imágenes parece apreciarse incluso un gancho en la horizontal junto al máximo de reflectividad. No se dispone de imágenes de viento radial debido a la lejanía respecto al radar de Sevilla. Tampoco se han podido hacer cortes verticales. No obstante, no parece aven-

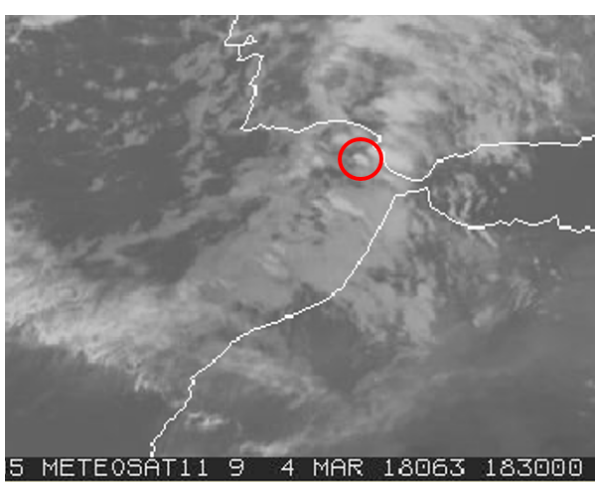

Figura 13. Imagen del canal IR10,8 de METEOSAT 11 a las 18:30 UTC. turado suponer que, de modo similar a las células de Huelva, pudiera tratarse de una célula con una estructura rotatoria en su seno, dado el patrón de reflectividad observado y las condiciones favorables para ello.

a)

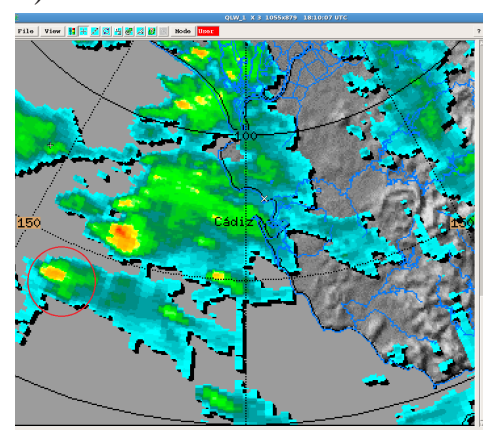

b)

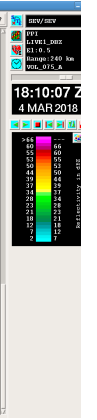

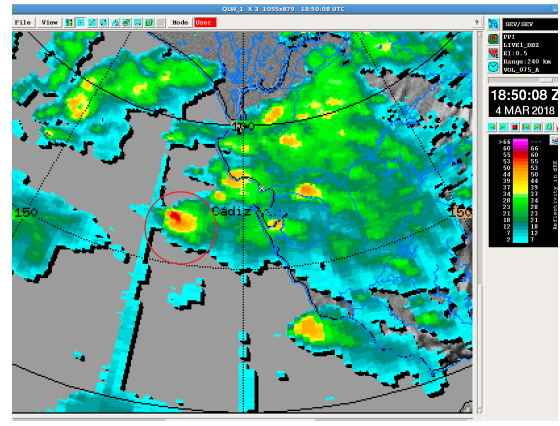

c)

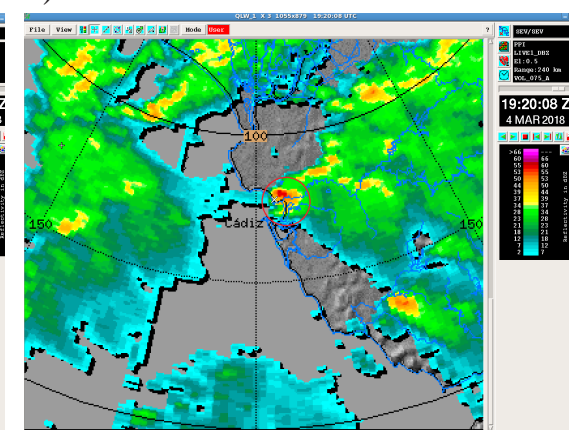

Figura 14. Radar de Sevilla. Imágenes PPI de reflectividad. Elevación 0,5. a) A las 18:10 UTC. b) A las 18:50. c) Y a las 19:20 UTC. Se marca con un círculo rojo la célula generadora del tornado y con un aspa la ubicación de Puerto Sherry.

\subsection{Efectos en superficie}

Se realiza visita a la zona afectada a la mañana siguiente, mientras se encuentran activas todavía las tareas de recogida y limpieza. A partir de los daños observados y los testimonios recogidos se deduce que el tornado entra desde el mar, por la zona de Puerto Sherry, causando daños en árboles, fachadas, vehículos y de forma muy llamativa derribando numerosos barcos grandes en dique seco. Vuelve a tocar tierra por la desembocadura del Guadalete, causando daños en naves industriales y arbolado. Atraviesa después zona urbana, dañando tejados, vallas y árboles.

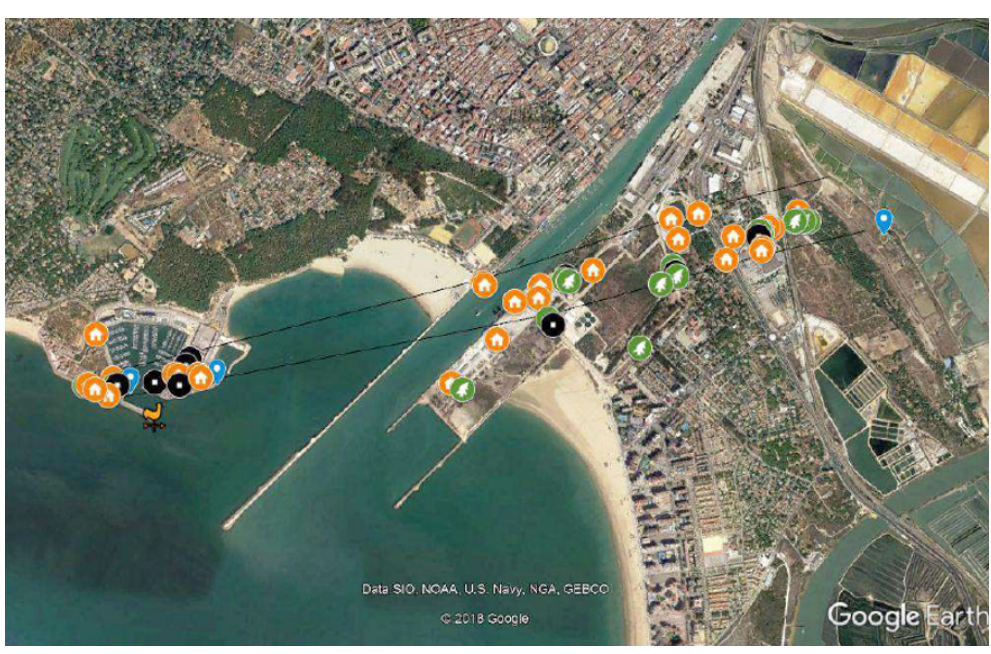

Figura 15. Ubicación de los daños producidos por el tornado en El Puerto de Santa María.

Finalmente sale por la marisma del Guadalete, donde se pierde el rastro. La franja de daños (fig. 15) tiene $4,5 \mathrm{~km}$ de longitud y una anchura inicial de $80 \mathrm{~m}$ y máxima de $300 \mathrm{~m}$. 
Los daños más importantes se concentran en la zona de Puerto Sherry, donde la intensidad del tornado habría llegado a EF2. Algunos pueden verse en la figura 16.
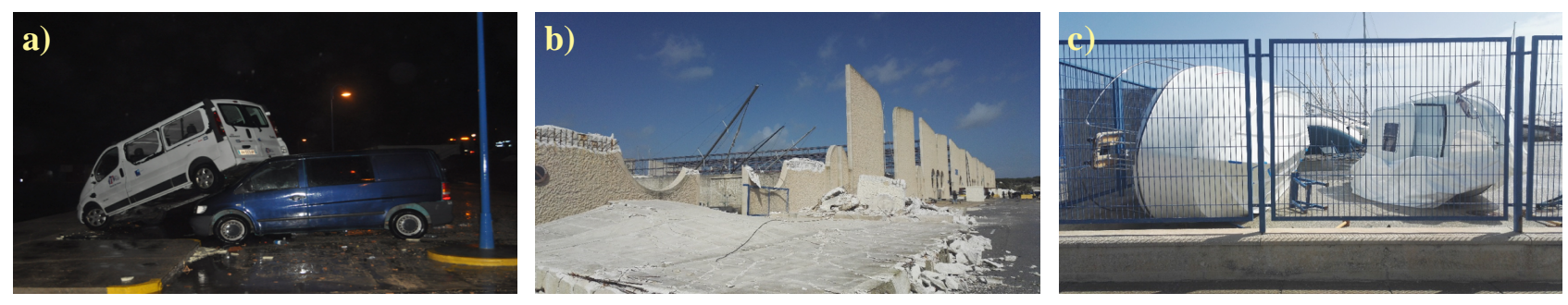

Figura 16. Imágenes de daños producidos en la zona de Puerto Sherry. a) Una furgoneta desplazada sobre otro coche y caída sobre un tercero. b) Muro cortavientos de hormigón, de doble capa y armado, de unos $40 \mathrm{~cm}$ de espesor, derribado. c) Grandes embarcaciones en dique seco derribadas y con importantes daños.

Se dispone del dato de racha máxima registrado en el faro del puerto, $130 \mathrm{~km} / \mathrm{h}$, a unos $30 \mathrm{~m}$ de altura y a unos $150 \mathrm{~m}$ de la zona con mayores daños. Dado el rápido decaimiento esperable del viento (aproximadamente con la inversa de la distancia) a partir del radio de viento máximo, este dato es perfectamente compatible con los valores del orden de $200 \mathrm{~km} / \mathrm{h}$ que corresponderían a una intensidad EF2 en la escala Fujita mejorada.

En el resto de la población los daños son de menor intensidad, aunque hay referencias de una casa prefabricada destruida casi por completo a la salida del pueblo hacia las marismas del Guadalete.

\section{CONCLUSIONES}

Se ha analizado el episodio múltiple de tornados del 4 de marzo de 2018 en Andalucía occidental. Se ha presentado como ejemplo que contiene una serie de características comunes a otros episodios similares:

- Desde el punto de vista sinóptico ocurre en una situación de borrasca atlántica durante la estación fría.

- Desde el punto de vista de ingredientes convectivos, ocurre en un entorno HSLC, o de elevada cizalladura vertical y ligera inestabilidad, concentradas en niveles bajos.

- Como en otros casos similares, la convección responsable de la formación de los tornados se muestra embebida en una banda frontal.

- Una característica común a la inmensa mayoría de los episodios es la alta humedad en niveles bajos, que se traduce en bajos niveles de condensación.

- Y, por último, es un ejemplo de episodios donde la convección se presenta en modo «supercelular», es decir, en forma de células individuales, con rotación persistente en la corriente ascendente principal, aunque de dimensiones mucho más reducidas que las supercélulas típicas.

Pero este episodio presenta también características propias que lo hacen destacar frente a otros:

- Se forma una célula convectiva organizada con un ciclo de vida inusualmente largo, responsable de al menos dos tornados, y un tercero se forma en una célula que podríamos considerar gemela de la anterior, que se desplaza paralelamente a ella durante un gran trecho.

- Uno de los tornados que produce dicha célula puede ser el más largo de los que se tienen registros en España, pudiendo llegar a $48 \mathrm{~km}$ de recorrido por parte del Algarve y de la provincia de Huelva.

- En apenas 2 horas ocurren dos tornados de intensidad EF2 en la escala mejorada de Fujita asociados a la misma banda frontal y en provincias limítrofes. 
Este estudio puede servir de estímulo para avanzar en el conocimiento de este tipo de fenómenos en España, más frecuente de lo que se suele pensar y con graves consecuencias económicas e incluso, a veces, humanas. Particularmente sería muy interesante el mantenimiento de una base de datos de tornados en nuestro país, que contenga, además de la localización espacio-temporal, datos sobre longitud de la trayectoria, anchura, intensidad, situación sinóptica, ingredientes convectivos y patrones radar asociados. Se han hecho esfuerzos puntuales en este sentido, pero debe hacerse lo posible para que todos los casos sean analizados y clasificados, siguiendo una metodología común. Parte importante de esa tarea es la realización de estudios de campo, absolutamente necesarios para en primer lugar determinar el tipo de fenómeno causante de los daños, y después sus dimensiones e intensidad.

También será de mucho interés avanzar en el estudio y la caracterización de las situaciones potencialmente generadoras de tornados en España, así como en el máximo aprovechamiento de las herramientas de teledetección disponibles. De todo ello se podrían obtener importantes beneficios para la predicción operativa orientada a la elaboración de avisos de fenómenos adversos.

\section{AGRADECIMIENTOS}

A Paulo Jorge Pinto y Tania Viegas, del Instituto Português do Mar e da Atmosfera, por la información suministrada sobre los tornados del Algarve y sus comentarios sobre los mismos.

A los ayuntamientos de Ayamonte, Isla Cristina, Lepe, Cartaya, Aljaraque, Gibraleón, Huelva, Trigueros y Beas por la información suministrada sobre la afectación a sus respectivos municipios.

Al 112 Andalucía por los datos de incidencias de la tarde del día 4 de marzo en la provincia de Huelva.

Al puerto deportivo de Puerto Sherry, por la información suministrada sobre los daños en sus instalaciones y por las medidas de su estación meteorológica facilitadas.

\section{REFERENCIAS}

Brooks, H.E., 2004. On the relationship of tornado path length and width to intensity. Weather and Forecasting, 19 (2), 310-319.

DAVIS, J. M. y PARKER, M. D., 2014. Radar climatology of tornadic and nontornadic vortices in high-shear, low-CAPE environments in the mid-Atlantic and southeastern United States. Weather and Forecasting, $29(4), 828-853$.

Guyer, J. L. y Dean, A. R., 2010. 1.5 Tornadoes Within Weak Cape Environments Across The Continental United States. Database, vol. 2587, p. 6734.

Kennedy, P. C., Westcott, N.E. y Scott, R. W., 1993. Single-Doppler radar observations of a mini-supercell tornadic thunderstorm. Monthly weather review, 121 (6), 1860-1870.

MARKowski, P. M. y STRAKA, J. M., 2000. Some observations of rotating updrafts in a low-buoyancy, highly sheared environment. Monthly weather review, 128 (2), 449-461.

Riesco Martín, J. et al., 2015 Climatología de tornados en España Peninsular y Baleares. 2015. http://hdl.handle.net/20.500.11765/713.

Sherburn, K. D. y PARKer, M. D., 2014. Climatology and ingredients of significant severe convection in high-shear, low-CAPE environments. Weather and forecasting, 29 (4), 854-877. 
Sherburn, K. D., Parker, M. D., King, J. R. y Lackmann, G. M., 2016. Composite environments of severe and nonsevere high-shear, low-CAPE convective events. Weather and forecasting, 31 (6), 1899-1927.

SINOBAS: reporte del tornado del 4 de marzo de 2018 en El Puerto de Santa María.

SINOBAS: reporte del tornado del 4 de marzo de 2018 entre Ayamonte y Cartaya.

SINOBAS: reporte del tornado del 4 de marzo de 2018 entre Huelva y Beas

Soriano Romero, J. D. y Gutiérrez Rubio, D., 2016. Tornado del 11 de noviembre de 2014 en el Bajo Guadalquivir. XXXIV Jornadas Científicas de la Asociación Meteorológica Española. http://hdl.handle.net/ 20.500.11765/6156.

WiCKLER L. J. y CANTRELL, L., 1996. The role of vertical buoyancy distributions in miniature supercells. En: Preprints, 18th Conf. on Severe Local Storms, San Francisco, CA, Amer. Meteor. Soc. pp. 225-229. 
